\title{
ARE THERE MAGNETIC MOMENTS AT THE TRANSITION METAL SITES IN FeAl, CoAl AND NiAl?
}

\author{
R. B. FRANKEL \\ Francis Bitter National Magnet Laboratory \\ Massachusetts Institute of Technology, \\ Cambridge, Massachusetts 02139, USA

\section{J. SELLMEYER *} \\ Center for Materials Science and Engineering, \\ Massachusetts Institute of Technology, \\ Cambridge, Massachusetts 02139, USA \\ and

\section{N. A. BLUM} \\ Applied Physics Laboratory, Johns Hopkins University, \\ Silver Spring, Maryland, USA
}

\begin{abstract}
Measurements of the hyperfine interactions in ${ }^{57} \mathrm{Fe}$ in the $\mathrm{CsCl}$ structure intermetallic compounds FeAl, CoAl and NiAl are reported.
\end{abstract}

The binary alloys of $\mathrm{Fe}, \mathrm{Co}$ and $\mathrm{Ni}$ with $\mathrm{Al}$ form ordered, bcc structures in the 50-50 atomic percent composition range. Transport, susceptibility, NMR and Mössbauer measurements $[1-8]$ have suggested a model in which those transition metal ions which are in sites with all Al nearest neighbors have no localized magnetic moments, whereas ions in the normally Al sites with all transition metal ions nearest neighbors do have a localized magnetic moment. Thus the perfectly ordered 50-50 alloys would be essentially nonmagnetic, whereas alloys with excess $\mathrm{Fe}$, Co or Ni would be paramagnetic with the magnetism localized upon those excess ions occupying the Al sites. Magnetization measurements [5] in FeAl have shown a peak in the susceptibility at $2.5 \mathrm{~K}$ which has been ascribed to antiferromagnetic ordering.

To investigate this model we diffused ${ }^{57} \mathrm{Co}$ into samples of ordered $\mathrm{FeAl}, \mathrm{CoAl}$ and $\mathrm{NiAl}$ close to 50-50 atomic percent and observed the

* Supported by the U.S. Air Force Office of Scientific Research.

* Supported by Advanced Research Projects Agency.
Mossbauer resonance in $57 \mathrm{Fe}$ following the radioactive decay of the ${ }^{57} \mathrm{Co}$ (the samples were taken from those used in the transport measurements) [1]. In $\mathrm{FeAl}$ and $\mathrm{NiAl}$ we observed single unsplit lines at all temperatures from $1.2 \mathrm{~K}$ to $300 \mathrm{~K}$ with an isomer shift at room temperature relative to sodium ferrocyanide of $+0.36 \mathrm{~mm} / \mathrm{sec}$. In $\mathrm{CoAl}$ the resonance was considerably broader and could be decomposed into two lines with isomer shifts at room temperature of $+0.36 \mathrm{~mm} / \mathrm{sec}$ and $+0.18 \mathrm{~mm} / \mathrm{sec}$. Measurements were also made in external magnetic fields up to $85 \mathrm{kOe}$ at $4.2 \mathrm{~K}$. In $\mathrm{FeAl}$ and NiAl the observed field at the nucleus $H_{\mathrm{n}}$ was equal to the external field $H_{0}$ for all applied fields. In CoAl the nuclei with isomer shift at room temperature of $+0.36 \mathrm{~mm} / \mathrm{sec}$ were also observed to have $H_{\mathrm{n}}=H_{0}$, while those with isomer shift $+0.18 \mathrm{~mm} / \mathrm{sec}$ at room temperature were observed to have $H_{\mathrm{n}}<H_{0}$, indicating a magnetic hyperfine interaction contribution to the observed field at the latter sites.

For $\mathrm{FeAl}$ and $\mathrm{NiAl}$ the results are consistent with the model outlined above, namely, that those transition metal ions in sites with all $\mathrm{Al}$ nearest neighbors have no magnetic moment. If 
there were a moment, we would have expected a hyperfine contribution to the observed fields at the nucleus. Also, since we observe a single, unsplit line in $\mathrm{FeAl}$ down to $1.2 \mathrm{~K}$, we suggest that the anomaly in the susceptibility at $2.5 \mathrm{~K}$ is not due to an antiferromagnetic transition involving moments localized at the Fe sites. Because most of the ${ }^{57} \mathrm{Co}$ diffused into the $\mathrm{FeAl}$ and $\mathrm{NiAl}$ presumably went into transition metal sites, we were not able to measure the hyperfine interactions for $\mathrm{Fe}$ in the $\mathrm{Al}$ sites of these alloys.

In $\mathrm{CoAl}$ the results are anomalous. We find iron nuclei with no induced hyperfine field (i.e., $\left.H_{\mathrm{n}} \cdot H_{\mathrm{O}}\right)$ at high external field and low temperature as in $\mathrm{FeAl}$ and $\mathrm{NiAl}$ [3]. For the nuclei with $H_{\mathrm{n}} r H_{0}$, and isomer shift of $+0.18 \mathrm{~mm} / \mathrm{sec}$, we infer that they are located in $\mathrm{Al}$ sites in the alloy. Because the spectra for these nuclei are not well resolved we can only estimate that the hyperfine field $H_{\mathrm{hf}}\left(=H_{\mathrm{n}}-H_{\mathrm{O}}\right) \approx 110 \mathrm{kOe}$, i.e. roughly the same as that for the ferromagnetic sublattice in $\mathrm{Fe}_{1.1} \mathrm{Al}_{0.9}$ [4]. Furthermore, measurements at low $T$ and low $H_{0}$ indicate that the hyperfine field does not follow a Brillouin function of $H_{0}$ and $T$, i.e. there is a possibility of spin compensation of the localized spins in the essentially non-magnetic background. This may be compared with transport and susceptibility evidence for a Kondo effect in $\mathrm{Co}$ in the $\mathrm{Al}$ sites of $\mathrm{CoAl}[1,9]$.

References

[1] G. R. Caskey and D. J. Sellmeyer, J. Appl. Phys, 40 (1969) 1476.

[2] K. Myatani and S. Ida, J. Phys. Soc. Japan 25 (1968) 1008.

[3] D. O. Van Ostenburg, J. J. Spokas, C. H. Dowers and H. G. Hoeve, Phys. Letters 30A (1969) 130

[4] G. K. Wertheim and J. H. Wernick, Acta Metalturgica 15 (1967) 297.

[5] H. Danan and H. Gengnagel, J. Appl. Phys, 39 (1968) 678.

[6] G. P. Huffman and R. M. Fischer, J. Appl. Phys. 38 (1967) 735.

[7] Y. Yamaguchi, T. Aoki and J. O. Brittain, J. Phys. Chem. Solids 31 (1970) 1325.

[8] M. B. Brodsky and J. O. Brittain, J. Appl. Phys. 40 (1969) 3615.

[9] D. J. Sellmeyer, G.R. Caskey and J.Franz, Bull, Am. Phys. Soc. 15 (1970) 292. 